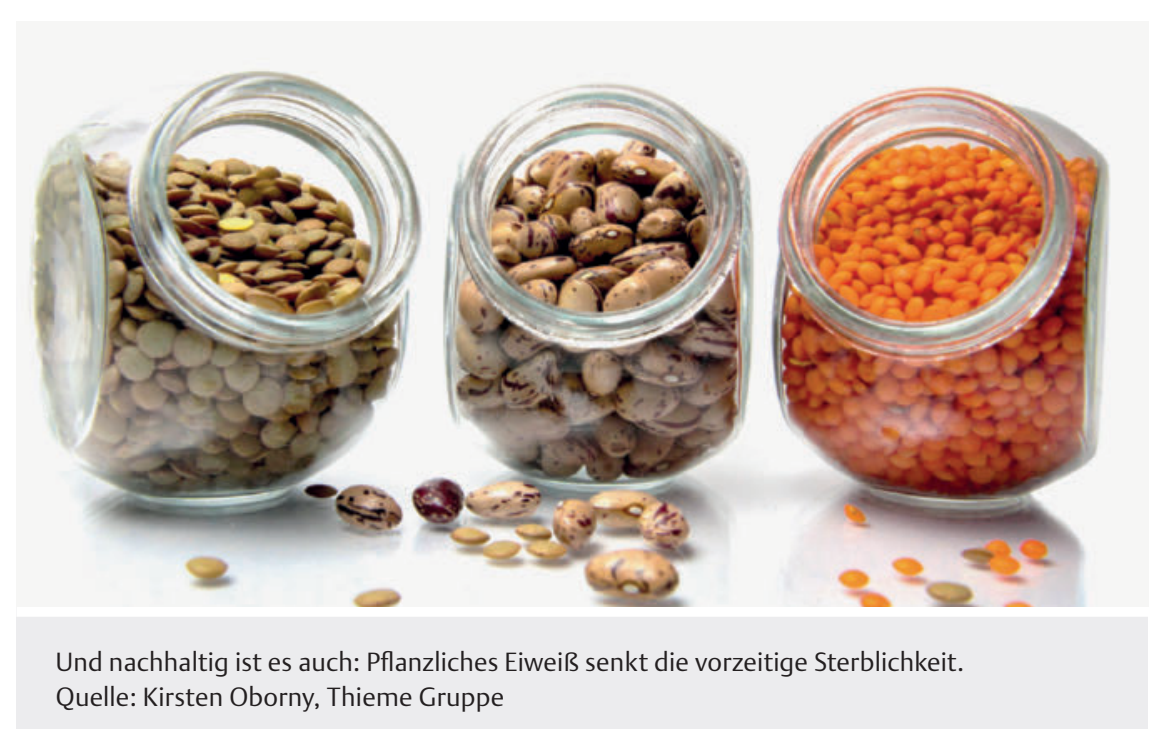

Gesunde Ernährung

\section{Pflanzliche Proteine verlängern das Leben}

Naghshi S et al. Dietary intake of total, animal, and plant proteins and risk of all cause, cardiovascular, and cancer mortality: systematic review and dose-response meta-analysis of protective cohort studies. BMJ 2020; 370: m2412

Proteinreiche Diäten sind populär. Sie sollen helfen, Übergewicht zu vermeiden, die Muskelmasse zu erhalten und kardiometabolische Parameter günstig zu beeinflussen. Eine Metaanalyse zeigte nun, dass insbesondere Proteine aus pflanzlichen Quellen sowohl die allgemeine als auch die kardiovaskuläre Mortalität senken können.

32 prospektive Studien mit insgesamt mehr als 700000 Teilnehmerinnen und Teilnehmern gingen in die Analysen ein. In 18 Studien war insbesondere der Einfluss pflanzlicher Proteine auf die Mortalität untersucht worden. Untersuchungen an Kindern und Jugendlichen sowie Patienten mit schweren Nierenerkrankungen, Malignomen im Endstadium oder anderen kritischen Er- krankungen wurden nicht einbezogen. Die Beobachtungszeit lag in den einzelnen Studien zwischen 3,5 und 32 Jahren. Die tägliche Aufnahme von Proteinen wurde entweder bei den Studienteilnehmern erfragt oder mithilfe der Harnstoffausscheidung im Urin ermittelt. Die Risikoberechnungen erfolgten anhand eines Random-Effects-Modells.

krankungen in Zusammenhang gebracht wird. Darüber hinaus können bakterielle Fermentationsprozesse pflanzlicher Proteine die Entstehung toxischer Metabolite im Darm verringern. Bioaktive Peptide pflanzlicher Herkunft zeigten außerdem in früheren Studien antioxidative und antiinflammatorische Eigenschaften. Letztlich scheint auch die Aminosäuren-Zusammensetzung bei Proteinen pflanzlicher Herkunft günstige Effekte auf den Lipidstoffwechsel und die Blutzuckerregulierung zu haben. Klinisch konnten in vorausgehenden Studien günstige Effekte pflanzlicher Proteine auf den arteriellen Blutdruck, den Hüftumfang und das Körpergewicht nachgewiesen werden. Dennoch weisen die Autoren darauf hin, dass die Aufnahme pflanzlicher bzw. tierischer Proteine immer im Zusammenhang mit einer Gesamternährungsweise zu sehen sei. licher Proteine sowohl mit einer verringerten Gesamtmortalität als auch mit einer verringerten kardiovaskulären Mortalität einherging. Die Ergebnisse waren konsistent für unterschiedliche Body-Mass-Indizes und Gesamtenergieaufnahmen. In einer Dosis-Wirkungs-Analyse zeigte sich, dass eine Steigerung der Aufnahme pflanzlicher Proteine um $3 \%$ zu einer Verringerung der Gesamtmortalität um 5 \% führte.

\section{Wie wirkt pflanzliches Protein?}

Als mögliche Mechanismen der günstigen Wirkung pflanzlicher Proteine diskutieren die Autoren den fehlenden Anstieg des Insulin-like Growth Factors 1, der typischerweise nach dem Verzehr tierischer Proteine auftritt und mit altersbedingten $\mathrm{Er}$ -

\section{FAZIT}

Pflanzliche Proteine, die sich beispielsweise in Hülsenfrüchten, Nüssen und Saaten finden, scheinen das Leben zu verlängern. Dabei wirkt sich schon eine geringe Steigerung des Anteils pflanzlicher Proteine in der Ernährung deutlich auf die Mortalität aus. Die Ergebnisse unterstreichen die aktuellen Ernährungsempfehlungen der internationalen Fachgesellschaften, so die Autoren.

Dr. Katharina Franke, Darmstadt 